\title{
Installation Problem Identified
}

National Cancer Institute

\section{Source}

National Cancer Institute. Installation Problem Identified. NCI Thesaurus. Code C92067.

A device that malfunctions because it was incorrectly installed, set-up, or configured (e.g. misconfiguration of an "automatic" defibrillator to "semi-automatic", thereby leading to failure). 